\title{
Effects of inhaler therapy on mortality in patients with tuberculous destroyed lung and airflow limitation
}

This article was published in the following Dove Medical Press journal:

Therapeutics and Clinical Risk Management

\author{
Ho Cheol Kim ${ }^{1, *}$ \\ Tae Hoon $\mathrm{Kim}^{2, *}$ \\ Chin Kook Rhee ${ }^{3}$ \\ Minkyu Han ${ }^{4}$ \\ Yeon-Mok Oh' \\ 'Department of Pulmonary and \\ Critical Care Medicine, Asan Medical \\ Center, University of Ulsan College of \\ Medicine, Seoul, Korea; ${ }^{2}$ Department \\ of Internal Medicine, CHA Bundang \\ Medical Center, CHA University, \\ Seongnam, Korea; ${ }^{3}$ Division of \\ Pulmonary, Allergy and Critical Care \\ Medicine, Department of Internal \\ Medicine, Seoul St. Mary's Hospital, \\ College of Medicine, The Catholic \\ University of Korea, Seoul, Korea; \\ ${ }^{4}$ Department of Clinical Epidemiology \\ and Biostatistics, Asan Medical \\ Center, University of Ulsan College of \\ Medicine, Seoul, Korea \\ *These authors contributed equally \\ to this work
}

Purpose: Although patients with tuberculous destroyed lung (TDL) receive long-acting muscarinic antagonist (LAMA) inhaler therapy, its effectiveness is not clear. This study evaluated the effect of LAMA inhaler therapy on mortality in patients with TDL and airflow limitation. Patients and methods: A retrospective cohort of 683 patients with TDL and airflow limitation was analyzed in this study. The mortality was compared between 177 patients treated with LAMA inhalers $>360$ days (LAMA group) and 506 patients not treated with LAMA inhalers or treated with LAMA inhalers for $<360$ days (non-LAMA group). Risk factors for mortality were analyzed with Cox proportional hazards models and survival analysis was performed after propensity score matching.

Results: Patients in the LAMA group appeared to have worse baseline characteristics, older mean age, lower lung function, higher X-ray severity, and were more likely to receive long-term oxygen therapy than those in the non-LAMA group. On multivariate analysis, LAMA inhaler usage was independently associated with lower risk of mortality $(\mathrm{HR}, 0.405 ; P=0.006)$ after adjusting age, gender, body mass index, smoking history, Charlson Comorbidity Index, lung function, X-ray severity, and long-term oxygen therapy. After propensity score matching to adjust for the above unbalanced baseline characteristics, patients in the LAMA group tended to have a better prognosis than those in the non-LAMA group (121 patients in each group, 5-year mortality rate: $2.5 \% \mathrm{vs} 9.1 \%, P=0.057$ ). If we performed the same analysis of propensity score matching even after excluding patients with corticosteroids/long-acting beta-2 agonist (ICS/ LABA) usage, patients in the LAMA group had a better prognosis than those in the non-LAMA group (64 patients in each group, 5-year mortality rate: $3.1 \%$ vs $14.1 \%, P=0.039$ ).

Conclusion: LAMA inhaler treatment might reduce mortality in patients with TDL and airflow limitation.

Keywords: tuberculosis, long-acting muscarinic antagonist, propensity score, survival

\section{Introduction}

Tuberculosis (TB) is a global health problem, and 10.0 million new cases were reported and an estimated 1.3 million deaths occurred due to TB in $2017 .{ }^{1}$ To facilitate the elimination of TB, numerous evidence-based guidelines have been developed for the standard management of TB. However, no standard management protocol has been developed for patients with tuberculous destroyed lung (TDL), possibly because studies targeting TDL (especially randomized controlled trials or observational studies) have rarely been performed and no medications targeting TDL have been developed. Even TB that was treated many years ago, may cause destruction of the lung, which can last for long period time after initial diagnosis or treatment of $\mathrm{TB}^{2}$ The impairment
Correspondence: Yeon-Mok Oh Department of Pulmonary and Critical Care Medicine, Asan Medical Center University of Ulsan College of Medicine, 88, Olympic-ro 43-gil, Songpa-gu, Seoul, 05505, South Korea

Tel +82230103136

Fax +82230106968

Email ymoh55@amc.seoul.kr 
in lung function can cause airflow limitation, ${ }^{3-5}$ which might affect the clinical outcome. ${ }^{6}$ However, the prevalence, clinical manifestations, and optimal treatment of patients with TDL, as well as airflow limitation in these patients, have not been well investigated.

Despite the lack of standard therapy in patients with TDL, inhaler therapies such as inhaled long-acting muscarinic antagonist (LAMA) or corticosteroids/long-acting beta-2 agonist (ICS/LABA), are often used in these patients. ${ }^{7}$ Yum et $\mathrm{al}^{8}$ found that inhaled tiotropium might improve lung function in patients with TDL, and Kim et $\mathrm{al}^{9}$ recently showed that inhaled indacaterol improved lung function and symptom control in patients with TDL. However, these previous studies were performed using a short-term period of $\sim 2$ months; therefore, long-term outcomes, such as mortality, could not be evaluated. In addition, these studies included patients without airflow limitation, so the efficacy of inhaler therapies might have been affected.

Therefore, the current study aimed to investigate clinical characteristics and the effect of inhaler therapy on mortality in patients with TDL and airflow limitation in South Korea, a country with an intermediate TB burden.

\section{Study population and methods Study design and populations}

We identified a total of 1,725 patients diagnosed with TDL between January 2000 and December 2014 from the electronic medical records at Asan Medical Center, a tertiary referral hospital, in South Korea. In this study, TDL is defined as parenchymal damage on chest radiograph due to sequelae from past TB, and the airflow limitation is defined as $\mathrm{FEV}_{1} / \mathrm{FVC}<70 \%$. Among the 1,725 patients, 500 patients who had been followed up for $<360$ days were excluded from this study in order to evaluate the long-term effect of inhaler therapy on mortality; in addition, 542 patients who had no airflow limitation at baseline pulmonary function test were also excluded from this study. Subsequently, the included patients were classified into the following groups based on the types of inhaler therapy that patients received: LAMA group and non-LAMA group or ICS/LABA group and non-ICS/LABA group. The LAMA group comprised patients who had been prescribed the tiotropium inhaler for $\geq 360$ days during the follow-up period to investigate the effect in a relatively adherent group over a period of time; the non-LAMA group included patients who never had been prescribed tiotropium inhaler and those who had been prescribed the inhaler for $<360$ days during the follow-up period. In addition, the ICS/LABA group included patients who had been prescribed the fluticasone propionate/salmeterol or budesonide/formoterol inhaler for $\geq 360$ days during the follow-up period, and the non-ICS/ LABA group comprised patients who never had been prescribed the fluticasone propionate/salmeterol or budesonide/ formoterol inhaler and those who had been prescribed the inhaler for $<360$ days during the follow-up period. The study flow chart is shown in Figure 1. The study protocol was approved by the Institutional Review Board of Asan Medical Center (2016-1028). The patient data were anonymized or maintained with confidentiality, in accordance with the Declaration of Helsinki. Because this study comprised a retrospective review of medical records, written informed consent was waived.

\section{Data collection}

Data regarding age, gender, body mass index (BMI), smoking history, mMRC score, ${ }^{10}$ comorbidity measured by the Charlson Comorbidity Index (CCI), ${ }^{11}$ pulmonary function tests, prescription of LAMA or ICS/LABA inhaler, and usage of home oxygen were collected from electronic medical records. Pulmonary functions were measured according to American Thoracic Society recommendations, and the results are expressed as percentages of normal predicted values. ${ }^{12}$ To evaluate the severity of TDL on the posteroanterior chest radiograph, six regions of the lung (ie, upper, middle, and lower regions of the right and left lungs) were semi-quantified with a total severity score of $0-6 .^{7}$ Clinical follow-up courses, including mortality of the patients until December 2016, were obtained from the data of the Korean national health insurance, in addition to the electronic medical records.

\section{Statistical analysis}

Data collected from the inhaler therapy and non-inhaler therapy groups were compared using Student's $t$-test or the Mann-Whitney U test for continuous variables and the chisquared test or Fisher's exact test for categorical variables. All $P$-values were two-tailed, with statistical significance set at $P<0.05$. Risk factors for mortality were analyzed with Cox proportional hazards models. Variables with a $P$-value $<0.20$ in the univariate analysis were used in the multivariate analysis. To avoid bias from the retrospective design in this cohort study, we performed propensity score matching to reduce potential confounding by non-random assignment or unbalanced covariates between LAMA and non-LAMA groups. The propensity score was calculated using logistic regression analysis with the following covariates: age, gender, BMI, 


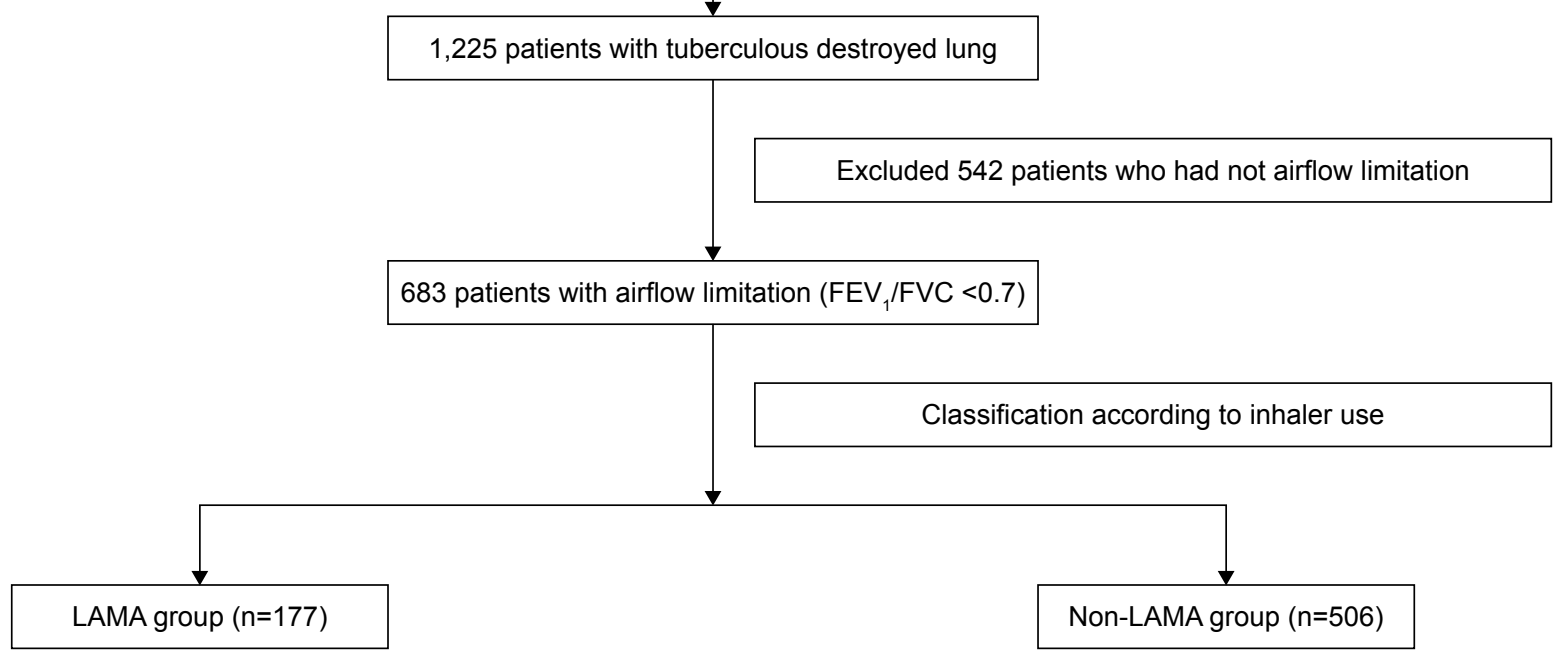

Figure I Study flow chart.

Abbreviation: LAMA, long-acting muscarinic antagonist.

smoking history, mMRC dyspnea score, CCI, concomitant asthma and COPD diagnosis, ICS/LABA inhaler usage over 360 days, pulmonary function tests, X-ray severity, and home oxygen usage. We compared the matched group using paired $t$-test or the paired Wilcoxon test (continuous variables) and the McNemar test (categorical data). The Kaplan-Meier survival analysis and log rank test were used to evaluate differences in mortality. All statistical analyses were performed using R software 3.5.1 version ( $\mathrm{R}$ Foundation for Statistical Computing, Vienna, Austria) and SPSS 22.0 software (IBM Corporation, Armonk, NY, USA).

\section{Results}

\section{Patient characteristics}

Among 683 patients with TDL and airflow limitation, 177 patients $(25.9 \%)$ received LAMA inhaler treatment over 360 days (LAMA group) and 171 patients $(25.0 \%)$ received ICS/LABA inhaler treatment over 360 days (ICS/LABA group). Patients in the LAMA group appeared to have worse baseline characteristics than did those in the non-LAMA group (Table 1). Patients in the LAMA group were older (63.9 vs 61.3 years, $P=0.004$ ), had higher mMRC dyspnea scale, and proportion of concomitant asthma (19.8\% vs $10.9 \%, P=0.003$ ) than those in the non-LAMA group. In addition, patients were more frequently prescribed ICS/LABA inhaler in the LAMA group than in the non-LAMA group
(18.8\% vs $2.9 \%, P<0.001)$. Baseline pulmonary functions were lower in the LAMA group than in the non-LAMA group (mean $\mathrm{FEV}_{1}: 40.7 \%$ vs $54.1 \%$ predicted, $P<0.001$ ), but X-ray severity ( 3.3 vs $2.9, P<0.001$ ), the proportion of respiratory admission within 2 years $(16.9 \%$ vs $9.3 \%, P=0.006)$, and long-term oxygen therapy $(16.9 \%$ vs $5.7 \%, P<0.001)$ were higher in the LAMA group than in the non-LAMA group.

Patients in the ICS/LABA group also had worse baseline characteristics than non-ICS/LABA group (Table 2). The mMRC dyspnea scale score, and the proportion of concomitant asthma (30.4\% vs $7.4 \%, P<0.001)$, were higher in the ICS/LABA group than in the non-ICS/LABA group. In addition, patients were prescribed LAMA more frequently in the ICS/LABA group than in the non-ICS/LABA group (62.6\% vs $13.7 \%, P<0.001)$. Baseline pulmonary functions were lower in the ICS/LABA group (mean $\mathrm{FEV}_{1}: 40.2 \%$ vs $54.1 \%$ predicted, $P<0.001)$, whereas $\mathrm{X}$-ray severity $(3.3$ vs $2.9, P<0.001)$, and the proportion of long-term oxygen therapy $(18.1 \%$ vs $5.5 \%, P<0.001)$ were higher in the ICS/ LABA group than in the non-ICS/LABA group.

\section{Risk factors for mortality in patients with TDL and airflow limitation}

During the median follow-up period of 1,566 days, 73 (10.7\%) patients died. Univariate Cox proportional hazards modeling revealed that older age, male gender, lower 
Table I Baseline characteristics of patients with airflow limitation according to LAMA usage over 360 days

\begin{tabular}{|c|c|c|c|}
\hline & LAMA group* & Non-LAMA group & $P$-value \\
\hline Number of patients & $177(25.9)$ & $506(74.1)$ & \\
\hline Age, years & $63.9 \pm 10.0$ & $61.3 \pm 11.5$ & 0.004 \\
\hline Male gender & $132(74.6)$ & $339(67.0)$ & $0.06 I$ \\
\hline Body mass index, $\mathrm{kg} / \mathrm{m}^{2}$ & $21.7 \pm 3.4$ & $22.0 \pm 3.4$ & 0.272 \\
\hline Ever smoker & $113(63.8)$ & $291(57.5)$ & 0.140 \\
\hline mMRC dyspnea scale & & & $<0.001$ \\
\hline-0 & $27(15.3)$ & $196(38.9)$ & \\
\hline-1 & $69(39.2)$ & $166(32.9)$ & \\
\hline-2 & $44(25.0)$ & $80(15.9)$ & \\
\hline-3 & $24(13.6)$ & $45(8.9)$ & \\
\hline-4 & $12(6.8)$ & $17(3.4)$ & \\
\hline Charlson Comorbidity Index & $1.4 \pm 1.1$ & $1.5 \pm 1.4$ & 0.496 \\
\hline Concomitant asthma & $35(19.8)$ & $55(10.9)$ & 0.003 \\
\hline ICS/LABA usage over 360 days & I77 (I8.8) & $23(2.9)$ & $<0.001$ \\
\hline \multicolumn{4}{|l|}{ Pulmonary function tests } \\
\hline $\mathrm{FEV}_{1}, \%$ predicted & $40.7 \pm 13.0$ & $54.1 \pm 20.2$ & $<0.001$ \\
\hline FVC, \% predicted & $63.1 \pm 16.0$ & $71.1 \pm 19.4$ & $<0.001$ \\
\hline $\mathrm{FEV}_{1} / \mathrm{FVC}$ ratio, $\%$ & $48.0 \pm 11.1$ & $54.9 \pm 10.9$ & $<0.001$ \\
\hline DLco, \% predicted & $56.7 \pm 22.1$ & $71.5 \pm 20.2$ & $<0.001$ \\
\hline Respiratory admission within 2 years & $30(16.9)$ & $47(9.3)$ & 0.006 \\
\hline X-ray severity (0-6) & $3.3 \pm 1.3$ & $2.9 \pm 1.3$ & $<0.001$ \\
\hline Long-term oxygen therapy & $30(16.9)$ & $29(5.7)$ & $<0.001$ \\
\hline
\end{tabular}

Notes: Data are presented as mean \pm SD or number of patients (\%), unless otherwise indicated. *LAMA group included patients who were prescribed the tiotropium inhaler for $\geq 360$ days during the follow-up period.

Abbreviations: DLco, diffusing capacity for carbon monoxide; ICS/LABA, inhaled corticosteroid/long-acting beta-2 agonist; LAMA, long-acting muscarinic antagonist.

BMI, ever smoker, higher CCI, lower $\mathrm{FEV}_{1}$, severe chest $\mathrm{X}$-ray findings, and long-term oxygen usage were related to higher mortality. Multivariate Cox proportional hazards model analysis showed that age (HR, 1.059; $95 \% \mathrm{CI}$, $1.032-1.087 ; P<0.001$ ), BMI (HR, 0.892; 95\% CI, 0.826$0.964 ; P=0.004)$, CCI (HR, 1.495; 95\% CI, 1.315-1.700; $P<0.001$ ), and X-ray severity (HR, $1.244 ; 95 \% \mathrm{CI}, 1.004$ $1.541 ; P=0.045)$ were significant independent risk factors for mortality. LAMA inhaler usage was not a significant risk factor for mortality in the univariate analysis, but was associated with lower risk of mortality in the multivariate analysis (HR, 0.405; 95\% CI, 0.211-0.776; $P=0.006$, Table 3). However, ICS/LABA inhaler usage was not a significant risk factor for mortality in both univariate and multivariate analysis.

\section{Propensity score matching between LAMA and non-LAMA groups}

Because baseline pulmonary function and other baseline characteristics in addition to ICS/LABA inhaler usage were significantly different between LAMA and non-LAMA, patients were matched based on the logit of the propensity score. After propensity score matching, 121 patients were selected from each group. Furthermore, we performed additional propensity score matching after patients with ICS/LABA inhaler usage over 360 days were excluded; 64 patients were selected from each of the LAMA and nonLAMA groups. Baseline characteristics were not different between LAMA and non-LAMA groups after the two propensity score matchings analyses (Table 4).

\section{Comparison of mortality between LAMA and non-LAMA groups before and after propensity score matching}

Kaplan-Meier survival analysis showed no significant differences between LAMA and non-LAMA groups before propensity score matching (Figure $2 \mathrm{~A}, P=0.115$ ). However, after propensity score matching, the survival period in the LAMA group was significantly longer than that in the non-LAMA group (Figure 2B, $P=0.002$ ). The results were similar even after patients with ICS/LABA usage were excluded (Figure 2C, $P=0.043$ ). Three sets of analyses 
Table 2 Baseline characteristics of patients with airflow limitation according to ICS/LABA usage over 360 days

\begin{tabular}{|c|c|c|c|}
\hline & ICS/LABA group* & Non-ICS/LABA group & $P$-value \\
\hline Number of patients & $|7|(25.0)$ & $512(75.0)$ & \\
\hline Age (years) & $61.9 \pm 10.8$ & $62.0 \pm 11.4$ & 0.930 \\
\hline Male gender & $119(69.6)$ & $352(68.8)$ & 0.837 \\
\hline Body mass index, $\mathrm{kg} / \mathrm{m}^{2}$ & $21.9 \pm 3.6$ & $21.9 \pm 3.4$ & 0.969 \\
\hline Ever smoker & $107(62.6)$ & $297(58.0)$ & 0.293 \\
\hline mMRC dyspnea scale & & & $<0.001$ \\
\hline-0 & $22(12.9)$ & $20 \mathrm{I}(39.4)$ & \\
\hline-1 & $59(34.7)$ & $176(34.5)$ & \\
\hline-2 & $47(27.6)$ & $77(15.1)$ & \\
\hline-3 & $29(17.1)$ & $40(7.8)$ & \\
\hline-4 & $13(7.6)$ & $16(3.1)$ & \\
\hline Charlson Comorbidity Index & $1.3 \pm 1.1$ & $1.5 \pm 1.5$ & 0.017 \\
\hline Concomitant asthma & $52(30.4)$ & $38(7.4)$ & $<0.001$ \\
\hline LAMA usage over 360 days & $107(62.6)$ & $70(13.7)$ & $<0.001$ \\
\hline \multicolumn{4}{|l|}{ Pulmonary function tests } \\
\hline $\mathrm{FEV}_{1}, \%$ predicted & $40.2 \pm 13.0$ & $54.1 \pm 20.0$ & $<0.001$ \\
\hline FVC, \% predicted & $62.8 \pm 16.8$ & $71.1 \pm 19.1$ & $<0.001$ \\
\hline $\mathrm{FEV}_{1} / \mathrm{FVC}$ ratio, $\%$ & $47.6 \pm 10.8$ & $54.9 \pm 11.0$ & $<0.001$ \\
\hline DLco, \% predicted & $61.4 \pm 23.1$ & $70.1 \pm 20.7$ & 0.003 \\
\hline Respiratory admission within 2 years & $25(14.6)$ & $52(10.2)$ & 0.110 \\
\hline X-ray severity (0-6) & $3.3 \pm 1.4$ & $2.9 \pm 1.3$ & $<0.001$ \\
\hline Long-term oxygen therapy & $31(18.1)$ & $28(5.5)$ & $<0.001$ \\
\hline
\end{tabular}

Notes: Data are presented as mean \pm standard deviation or number of patients $(\%)$, unless otherwise indicated. *ICS/LABA group included patients who were prescribed the fluticasone propionate/salmeterol or budesonide/formoterol inhaler for $\geq 360$ days during the follow-up period.

Abbreviations: DLco, diffusing capacity for carbon monoxide; LAMA, long-acting muscarinic antagonist; ICS/LABA, inhaled corticosteroid/long-acting beta-2 agonist.

Table 3 Risk factors for mortality in tuberculous destroyed lung patients with airflow limitation

\begin{tabular}{|c|c|c|c|c|c|c|}
\hline & \multicolumn{3}{|c|}{ Univariate analysis } & \multicolumn{3}{|c|}{ Multivariate analysis } \\
\hline & HR & $95 \% \mathrm{Cl}$ & $P$-value & HR & $95 \% \mathrm{Cl}$ & $P$-value \\
\hline Age, years & 1.047 & $1.023-1.07 \mid$ & $<0.001$ & 1.059 & $1.032-1.087$ & $<0.001$ \\
\hline Male gender compared to female & 1.979 & I.104-3.547 & 0.022 & 1.239 & $0.576-2.666$ & 0.583 \\
\hline Body mass index & 0.876 & $0.813-0.943$ & $<0.001$ & 0.892 & $0.826-0.964$ & 0.004 \\
\hline Ever smoker & 1.509 & $0.926-2.460$ & 0.099 & 1.024 & $0.543-1.933$ & 0.941 \\
\hline mMRC dyspnea scale & & & 0.326 & & & \\
\hline 0 (reference) & 1.000 & & & & & \\
\hline 1 & 0.805 & $0.448-1.446$ & 0.805 & & & \\
\hline 2 & 0.973 & $0.486-1.948$ & 0.973 & & & \\
\hline 3 & 1.274 & $0.609-2.666$ & 0.520 & & & \\
\hline 4 & 2.201 & $0.836-5.793$ & 0.110 & & & \\
\hline Charlson Comorbidity Index & 1.553 & $1.374-1.756$ & $<0.001$ & 1.495 & $1.315-1.700$ & $<0.001$ \\
\hline Concomitant asthma & 0.654 & $0.313-1.364$ & 0.257 & & & \\
\hline LAMA usage & 0.609 & $0.326-1.135$ & 0.118 & 0.405 & $0.211-0.776$ & 0.006 \\
\hline ICS/LABA usage & 0.951 & $0.568-1.592$ & 0.848 & & & \\
\hline $\mathrm{FEV}_{1}, \%$ predicted & 0.984 & $0.97 \mathrm{I}-0.997$ & 0.015 & 0.985 & $0.970-1.001$ & 0.062 \\
\hline X-ray severity $(0-6)$ & 1.329 & $1.120-1.578$ & 0.001 & 1.244 & $|.004-1.54|$ & 0.045 \\
\hline Long-term oxygen therapy & 2.146 & $1.176-3.916$ & 0.013 & 1.301 & $0.686-2.466$ & 0.420 \\
\hline
\end{tabular}

Note: Cox proportional hazards analysis was performed.

Abbreviations: DLco, diffusing capacity for carbon monoxide; LAMA, long-acting muscarinic antagonist; ICS/LABA, inhaled corticosteroid/long-acting beta-2 agonist. 
Table 4 Baseline characteristics of patients in LAMA and non-LAMA groups after propensity score matching

\begin{tabular}{|c|c|c|c|c|c|c|c|c|}
\hline & \multicolumn{4}{|c|}{ Including patients with ICS/LABA usage } & \multicolumn{4}{|c|}{ Excluding patients with ICS/LABA usage } \\
\hline & $\begin{array}{l}\text { LAMA } \\
\text { group }\end{array}$ & $\begin{array}{l}\text { Non-LAMA } \\
\text { group }\end{array}$ & $P$-value & SMD & $\begin{array}{l}\text { LAMA } \\
\text { group }\end{array}$ & $\begin{array}{l}\text { Non-LAMA } \\
\text { group }\end{array}$ & $P$-value & SMD \\
\hline Number of patients & 121 & 121 & & & 64 & 64 & & \\
\hline Age (years) & $63.6 \pm 10.4$ & $62.4 \pm 10.1$ & 0.364 & 0.117 & $64.2 \pm 9.6$ & $64.7 \pm 10.0$ & 0.766 & 0.053 \\
\hline Male gender & $90(74.4)$ & 87 (7I.9) & 0.772 & 0.056 & $50(78.1)$ & 51 (79.7) & $>0.999$ & 0.038 \\
\hline Body mass index $\left(\mathrm{kg} / \mathrm{m}^{2}\right)$ & $21.7 \pm 3.4$ & $21.6 \pm 3.4$ & 0.794 & 0.034 & $21.2 \pm 3.2$ & $20.6 \pm 3.5$ & 0.297 & 0.185 \\
\hline Ever smoker & $78(64.5)$ & $76(62.8)$ & 0.894 & 0.034 & $42(65.6)$ & $45(70.3)$ & 0.705 & 0.101 \\
\hline mMRC dyspnea scale & & & 0.778 & 0.172 & & & 0.903 & 0.182 \\
\hline-0 & $23(19.0)$ & $24(19.8)$ & & & $15(23.4)$ & $16(25.0)$ & & \\
\hline-1 & $42(34.7)$ & $49(40.5)$ & & & $25(39.1)$ & $28(43.8)$ & & \\
\hline-2 & $34(28.1)$ & $32(26.5)$ & & & $17(26.6)$ & $13(20.3)$ & & \\
\hline-3 & $15(12.4)$ & $12(9.9)$ & & & $5(7.8)$ & $4(6.3)$ & & \\
\hline-4 & $7(5.8)$ & $4(3.3)$ & & & $2(3.1)$ & $3(4.7)$ & & \\
\hline Charlson Comorbidity Index & $1.4 \pm 1.1$ & $1.5 \pm 1.4$ & 0.796 & 0.033 & $1.5 \pm 1.2$ & $1.4 \pm 1.2$ & 0.829 & 0.038 \\
\hline Concomitant asthma & $24(19.8)$ & $22(18.2)$ & 0.870 & 0.042 & $5(7.8)$ & $3(4.7)$ & 0.715 & 0.129 \\
\hline ICS/LABA usage over 360 days & $53(43.8)$ & $54(44.6)$ & $>0.999$ & 0.017 & 0 & 0 & & \\
\hline \multicolumn{9}{|l|}{ Pulmonary function tests } \\
\hline $\mathrm{FEV}_{1}, \%$ predicted & $42.9 \pm 13.6$ & $43.5 \pm 14.8$ & 0.776 & 0.037 & $45.4 \pm I 4.6$ & $45.1 \pm 15.1$ & 0.906 & 0.021 \\
\hline FVC, \% predicted & $63.9 \pm 16.0$ & $65.2 \pm 18.6$ & 0.556 & 0.076 & $64.5 \pm 16.4$ & $63.8 \pm 18.3$ & 0.823 & 0.040 \\
\hline $\mathrm{FEV}_{1} /$ FVC ratio, \% & $49.8 \pm 11.0$ & $48.8 \pm 10.7$ & 0.478 & 0.091 & $52.2 \pm I I . I$ & $51.8 \pm 10.8$ & 0.822 & 0.040 \\
\hline DLco, \% predicted & $60.8 \pm 23.0$ & $66.7 \pm 20.3$ & 0.192 & 0.098 & $59.2 \pm 20.6$ & $63.4 \pm 22.0$ & 0.464 & 0.159 \\
\hline Respiratory admission within 2 years & $15(12.4)$ & $12(9.9)$ & 0.683 & 0.079 & $7(10.9)$ & $8(12.5)$ & $>0.999$ & 0.049 \\
\hline X-ray severity (0-6) & $3.2 \pm 1.3$ & $3.2 \pm 1.4$ & 0.732 & 0.044 & $3.2 \pm 1.2$ & $3.0 \pm 1.2$ & 0.374 & 0.158 \\
\hline Long-term oxygen therapy & $16(13.2)$ & $12(9.9)$ & 0.547 & 0.103 & $6(9.4)$ & $6(9.4)$ & $>0.999$ & 0 \\
\hline
\end{tabular}

Note: Data are presented as mean \pm standard deviation or number of patients (\%), unless otherwise indicated.

Abbreviations: DLco, diffusing capacity for carbon monoxide; ICS/LABA, inhaled corticosteroid/long-acting beta-2 agonist; LAMA, long-acting muscarinic antagonist; SMD, standardized mean differences.

(before propensity score matching, after propensity score matching including patients with ICS/LABA usage, and after propensity score matching excluding patients with ICS/ LABA usage) revealed that the follow-up period did not significantly differ between the LAMA and the non-LAMA groups (Table S1). Similar with Kaplan-Meier survival analysis, 5-year mortality rate was lower in the LAMA group than in the non-LAMA group after propensity score matching including patients with ICS/LABA usage (2.5 vs $9.1 \%$, $P=0.057$ ) and excluding patients with ICS/LABA usage ( 3.1 vs $14.1 \%, P=0.039)$.

\section{Discussion}

Our current study showed that the LAMA inhaler therapy might reduce mortality in patients with TDL and airflow limitation. Although LAMA inhaler was prescribed more often for patients with older age, more symptoms, and reduced lung function, the patients in the LAMA group showed lower overall mortality than patients in the non-LAMA group, after adjusting for unbalanced covariates. To the best of our knowledge, none of the prior studies investigated the role of inhaler therapy in the mortality of patients with TDL and airflow limitation.

Although there is no consensus standard treatment for patients with TDL and airflow limitation, inhaler therapy, such as inhaled LAMA or ICS/LABA, is often applied in real practice. ${ }^{7}$ LAMA inhaler has been widely used in COPD patients..$^{13}$ However, there are few data regarding the use of inhaler therapy in patients with TDL. A recent study found that among 29 patients with TDL, 20 patients (72\%) exhibited an increase of $>10 \%$ in $\mathrm{FEV}_{1}$ over baseline after 2 months of tiotropium treatment, ${ }^{8}$ and the results suggested that relaxation of the bronchial smooth muscle and/or reduction of airway secretion by tiotropium might improve pulmonary function. In our current study, we found that 177 patients (25.9\%) were prescribed LAMA inhaler for over 360 days. 

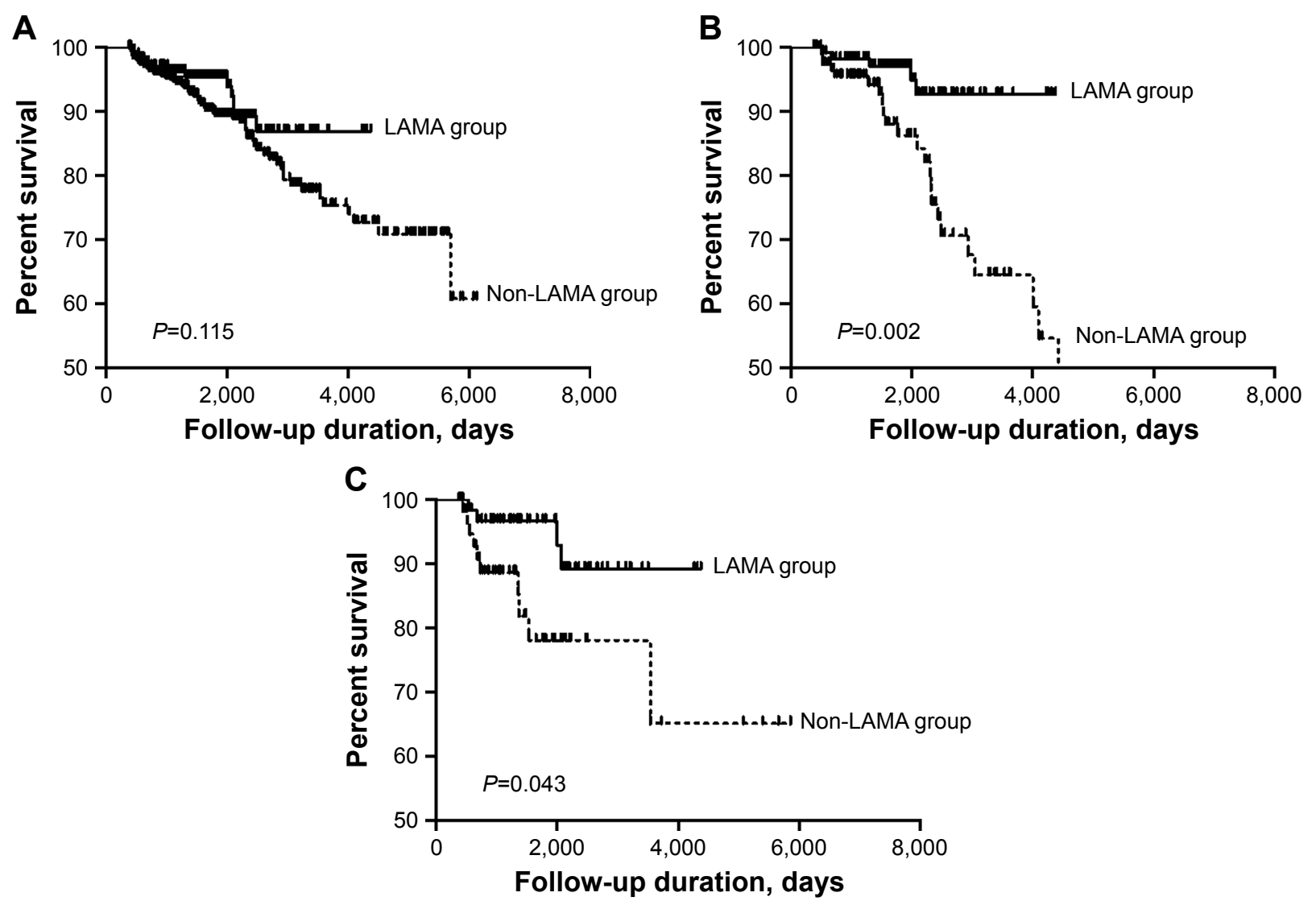

Figure 2 Comparison of Kaplan-Meier survival curves between LAMA and non-LAMA groups.

Notes: (A) Before propensity score matching, (B) after propensity score matching, including patients with inhaled corticosteroid/long-acting beta-2 agonist (ICS/LABA) usage, (C) after propensity score matching excluding patients with ICS/LABA usage. P-value from log rank test.

Abbreviation: ICS/LABA, inhaled corticosteroid/long-acting beta-2 agonist; LAMA, long-acting muscarinic antagonist.

Importantly, our study demonstrated that the prognosis of patients was better in the LAMA group than in the non-LAMA group, even after adjusting unbalanced covariates between two group and excluding patients with using ICS/LABA usage. These findings reinforce the importance of LAMA inhaler treatment for patients with TDL and airflow limitation.

Although the ICS/LABA inhaler has been used as one of the treatment options for patients with COPD, ${ }^{14}$ the LAMA inhaler alone or in the combination with the LABA inhaler is the preferred therapeutic option for patients with COPD because of its great efficacy and low adverse events, such as pneumonia. ${ }^{15,16}$ Previous studies reported an effect of inhaler on pulmonary function in patients with TDL. Kim et $\mathrm{al}^{9}$ reported that indacaterol group had improved $\mathrm{FEV}_{1}$ and transition dyspnea index compared with the placebo group in 119 patients with TDL and moderate to severe airflow limitation. In addition, Rhee et $\mathrm{al},{ }^{7}$ in 35 patients with TDL, reported that both LAMA and ICS/LABA inhaler usage significantly increased the $\mathrm{FEV}_{1}$ (respectively 0.14 and $0.28 \mathrm{~L}$ ) compared to those of patients who did not use medication $(0.01 \mathrm{~L}) .{ }^{7}$ However, no previous study has investigated the role of inhaler therapy on mortality in patients with TDL. In the current study, while the LAMA inhaler usage was favorable prognostic factor, the ICS/LABA inhaler usage was not associated with prognosis in patients with TDL and airflow limitation. The reason for this result is unclear, and one possible explanation is that our study included small number of patients with asthma or bronchodilator response. In fact, $13.2 \%$ of patients had concomitant asthma and $7.2 \%$ of patients with available post-bronchodilator pulmonary function test had a bronchodilator response in the current study. Notably, growing evidences indicate that ICS might increase the risk of pneumonia or reactivation of TB. ${ }^{17-19}$ Therefore, ICS/LABA inhaler should only be prescribed for a selected group of patients with TDL.

TB can cause the progressive and extensive destruction of lung parenchyma, and the damage may induce chronic airflow obstruction (with ranges of $30 \%-80 \%)$ ) $^{6,20-23}$ Furthermore, Plit et $\mathrm{al}^{24}$ showed that a substantial proportion of patients with TB had impaired lung function, even after successful TB treatment. The prevalence of airflow limitation in patients with TDL was $55.8 \%$ in our study, 
which is comparable with that in previous studies. A few studies have shown that airflow limitation might affect the clinical course of patients with TDL. Lee et $\mathrm{al}^{5}$ found that patients with airflow limitation and TDL had higher airflow resistance and lower positive bronchodilator response rates compared with COPD patients. Kim et $\mathrm{al}^{6}$ showed that airflow limitation was an independent risk factor for acute exacerbation (HR 1.634, $P=0.044$ ) in 158 patients with TDL. However, treatment information that could affect prognosis was not considered in that study. In addition, Rhee et $\mathrm{al}^{7}$ showed that the numbers of exacerbations did not differ in TDL patients with and without airflow limitation, although patients with airflow limitation had lower $\mathrm{FEV}_{1}$, these patients used LAMA or ICS/LABA more frequently than did those without airflow limitation in that study. In our current study, patients with airflow limitation tended to have worse prognosis than did those without airflow limitation group, with marginal significance $(P$-value $=0.067)$ (Figure S1). Although patients with airflow limitation had worse baseline characteristics than those without airflow limitation, inhaler therapy was prescribed more frequently in patients with airflow limitation than in those without airflow limitation (Table S2). These findings suggest that inhaler treatment might be associated with favorable prognosis in patients with TDL.

Beside LAMA inhaler usage, older age, lower BMI, and higher CCI were associated with higher mortality. These variables are relatively well known as predictors of poor prognosis in patients with COPD. ${ }^{25-27}$ In addition, the present study found that higher X-ray severity was associated with poor prognosis. The findings in the present study are supported by those in previous studies. Ryu et $\mathrm{al}^{28}$ found that the extent of the destroyed lung parenchyma was only independent prognostic factor for mortality in 169 patients with TDL (HR 3.52, $P=0.004$ ). Therefore, patients with severe lung destruction should be monitored carefully and treated actively.

In our study, subjects were followed up for a relatively long period of time (median, 1,566 days). Although the follow-up duration for the LAMA group was not different for the non-LAMA group after propensity score-matching analysis, the 5-year mortality rate was lower in the LAMA group than in the non-LAMA group. In addition, $\sim 50 \%$ of patients in the LAMA group had a medication possession ratio (MPR) $\geq 80 \%$, and these patients were classified as the "adherent group" in many previous studies. ${ }^{29-32}$ Collectively, these results indicate that LAMA inhaler therapy might be effective in reducing mortality in patients with TDL and airflow limitation.

This study has several limitations. First, our study was retrospective in nature. However, this study included a large number of patients with few missing data. In addition, we used a statistical method (propensity score analysis) to reduce confounding factors. Second, the treatment duration during the follow-up period was variable in the LAMA group. Although the LAMA group only included patients who used the LAMA inhaler for $>360$ days to enable evaluation of the long-term effect, 13 patients (7.3\% in the total LAMA group) were prescribed the LAMA inhaler for $<30 \%$ of the total follow-up period. These patients might have interfered with the accurate results in our study. Moreover, after propensity score matching, among patients in the non-LAMA group, 46 patients $(38.0 \%)$ were prescribed the LAMA inhaler $<1$ year (median treatment duration: 100 days). However, none of these patients had died, which might have some effect on the results of this study. Finally, our study included patients at a single referral center in South Korea. Thus, external validation studies with other populations of patients with TDL and airflow limitation are needed. On the other hand, our study has advantages in data collection. We collected survival information of all patients by using the national health insurance database in South Korea, which makes it possible to trace the death of patients. Since South Korea has a mandatory universal health insurance system for the entire Korean population, it provides an accurate and useful research source. ${ }^{33,34}$

\section{Conclusions}

The current study findings suggest that LAMA inhaler therapy might be associated with favorable prognosis in patients with TDL and airflow limitation. Therefore, LAMA inhaler therapy can be considered as a reasonable treatment option for these patients.

\section{Abbreviations}

TDL, tuberculous destroyed lung; LAMA, long-acting muscarinic antagonist; ICS/LABA, inhaled corticosteroid/ long-acting beta-2 agonist; BMI, body mass index; CCI, Charlson Comorbidity Index.

\section{Ethics approval}

The study protocol was approved by the Institutional Review Board of Asan Medical Center (2016-1028). Because this study comprised a retrospective review of medical records, written informed consent was waived. 


\section{Acknowledgments}

This study was supported by a grant of the Ministry of Health and Welfare, Republic of Korea (Grant No HC16C-2254-010017).

\section{Author contributions}

All authors contributed to data analysis, drafting and revising the article, gave final approval of the version to be published, and agree to be accountable for all aspects of the work.

\section{Disclosure}

CK Rhee received consulting/lecture fees from MSD, AstraZeneca, Novartis, Takeda, Mundipharma, BoehringerIngelheim, Teva, and Bayer. Other authors have no potential conflicts of interest to disclose in this work.

\section{References}

1. World Health Organization [homepage on the Internet]. Geneva: World Health Organization; c2018 [updated September 18, 2018; cited October 10, 2018]; 2018. Available from: http://www.who.int/tb/publications/ global_report/en/

2. Bobrowitz ID, Rodescu D, Marcus H, Abeles H. The destroyed tuberculous lung. Scand J Respir Dis. 1974;55(1):82-88.

3. Snider GL, Doctor L, Demas TA, Shaw AR. Obstructive airway disease in patients with treated pulmonary tuberculosis. Am Rev Respir Dis. 1971;103(5):625-640.

4. Lam KB, Jiang CQ, Jordan RE, et al. Prior TB, smoking, and airflow obstruction: a cross-sectional analysis of the Guangzhou Biobank Cohort study. Chest. 2010;137(3):593-600.

5. Lee JH, Chang JH. Lung function in patients with chronic airflow obstruction due to tuberculous destroyed lung. Respir Med. 2003;97(11):1237-1242.

6. Kim SJ, Lee J, Park YS, et al. Effect of airflow limitation on acute exacerbations in patients with destroyed lungs by tuberculosis. $J$ Korean Med Sci. 2015;30(6):737-742.

7. Rhee $\mathrm{CK}$, Yoo KH, Lee JH, et al. Clinical characteristics of patients with tuberculosis-destroyed lung. Int J Tuberc Lung Dis. 2013;17(1) $67-75$.

8. Yum H-K, Park I-N. Effect of inhaled tiotropium on Spirometric parameters in patients with tuberculous destroyed lung. Tuberc Respir Dis. 2014;77(4):167-171.

9. Kim CJ, Yoon HK, Park MJ, et al. Inhaled indacaterol for the treatment of COPD patients with destroyed lung by tuberculosis and moderateto-severe airflow limitation: results from the randomized infinity study. Int J Chron Obstruct Pulmon Dis. 2017;12:1589-1596.

10. Mahler DA, Wells CK. Evaluation of clinical methods for rating dyspnea. Chest. 1988;93(3):580-586.

11. Charlson ME, Pompei P, Ales KL, Mackenzie CR. A new method of classifying prognostic comorbidity in longitudinal studies: development and validation. J Chronic Dis. 1987;40(5):373-383.

12. Miller MR, Hankinson J, Brusasco V, et al. Standardisation of spirometry. Eur Respir J. 2005;26(2):319-338

13. Tashkin DP, Celli B, Senn S, et al. A 4-year trial of tiotropium in chronic obstructive pulmonary disease. $N$ Engl J Med. 2008;359(15): 1543-1554.

14. Calverley PM, Anderson JA, Celli B, et al. Salmeterol and fluticasone propionate and survival in chronic obstructive pulmonary disease N Engl J Med. 2007;356(8):775-789.
15. Wedzicha JA, Calverley PM, Seemungal TA, et al. The prevention of chronic obstructive pulmonary disease exacerbations by salmeterol/ fluticasone propionate or tiotropium bromide. Am J Respir Crit Care Med. 2008;177(1):19-26.

16. Wedzicha JA, Banerji D, Chapman KR, et al. IndacaterolGlycopyrronium versus Salmeterol-Fluticasone for COPD. NEngl J Med. 2016;374(23):2222-2234.

17. Lee CH, Kim K, Hyun MK, Jang EJ, Lee NR, Yim JJ. Use of inhaled corticosteroids and the risk of tuberculosis. Thorax. 2013; 68(12):1105-1113.

18. Kim JH, Park JS, Kim KH, Jeong HC, Kim EK, Lee JH. Inhaled corticosteroid is associated with an increased risk of TB in patients with COPD. Chest. 2013;143(4):1018-1024.

19. Suissa S, Patenaude V, Lapi F, Ernst P. Inhaled corticosteroids in COPD and the risk of serious pneumonia. Thorax. 2013;68(11):1029-1036.

20. Ehrlich RI, Adams S, Baatjies R, Jeebhay MF. Chronic airflow obstruction and respiratory symptoms following tuberculosis: a review of South African studies. Int J Tuberc Lung Dis. 2011;15(7):886-891.

21. Menezes AM, Hallal PC, Perez-Padilla R, et al. Tuberculosis and airflow obstruction: evidence from the PLATINO study in Latin America. Eur Respir J. 2007;30(6):1180-1185.

22. Willcox PA, Ferguson AD. Chronic obstructive airways disease following treated pulmonary tuberculosis. Respir Med. 1989;83(3):195-198.

23. Pasipanodya JG, Miller TL, Vecino M, et al. Pulmonary impairment after tuberculosis. Chest. 2007;131(6):1817-1824.

24. Plit ML, Anderson R, van Rensburg CE, et al. Influence of antimicrobial chemotherapy on Spirometric parameters and pro-inflammatory indices in severe pulmonary tuberculosis. Eur Respir J. 1998;12(2):351-356.

25. Soler-Cataluña JJ, Martínez-García MA, Román Sánchez P, Salcedo E, Navarro M, Ochando R. Severe acute exacerbations and mortality in patients with chronic obstructive pulmonary disease. Thorax. 2005;60(11):925-931.

26. Celli BR, Cote CG, Marin JM, et al. The body-mass index, airflow obstruction, dyspnea, and exercise capacity index in chronic obstructive pulmonary disease. $N$ Engl $J$ Med Overseas Ed. 2004;350(10): $1005-1012$.

27. Divo M, Cote C, de Torres JP, et al. Comorbidities and risk of mortality in patients with chronic obstructive pulmonary disease. Am J Respir Crit Care Med. 2012;186(2):155-161.

28. Ryu YJ, Lee JH, Chun EM, Chang JH, Shim SS. Clinical outcomes and prognostic factors in patients with tuberculous destroyed lung. Int J Tuberc Lung Dis. 2011;15(2):246i-250i.

29. Briesacher BA, Andrade SE, Fouayzi H, Chan KA. Medication adherence and use of generic drug therapies. Am J Manag Care. 2009;15(7): $450-456$.

30. Haupt D, Krigsman K, Nilsson JL. Medication persistence among patients with asthma/COPD drugs. Pharm World Sci. 2008;30(5): 509-514.

31. Ismaila A, Corriveau D, Vaillancourt J, et al. Impact of adherence to treatment with tiotropium and fluticasone propionate/salmeterol in chronic obstructive pulmonary diseases patients. Curr Med Res Opin. 2014;30(7):1427-1436.

32. Kim JA, Lim MK, Kim K, Park J, Rhee CK. Adherence to inhaled medications and its effect on healthcare utilization and costs among high-grade chronic obstructive pulmonary disease patients. Clin Drug Investig. 2018;38(4):333-340.

33. Rhee CK, Kim K, Yoon HK, et al. Natural course of early COPD Int J Chron Obstruct Pulmon Dis. 2017;12:663-668.

34. Lim JU, Kim K, Kim SH, et al. Comparative study on medical utilization and costs of chronic obstructive pulmonary disease with good lung function. Int J Chron Obstruct Pulmon Dis. 2017;12:2711-2721. 


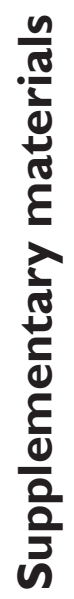

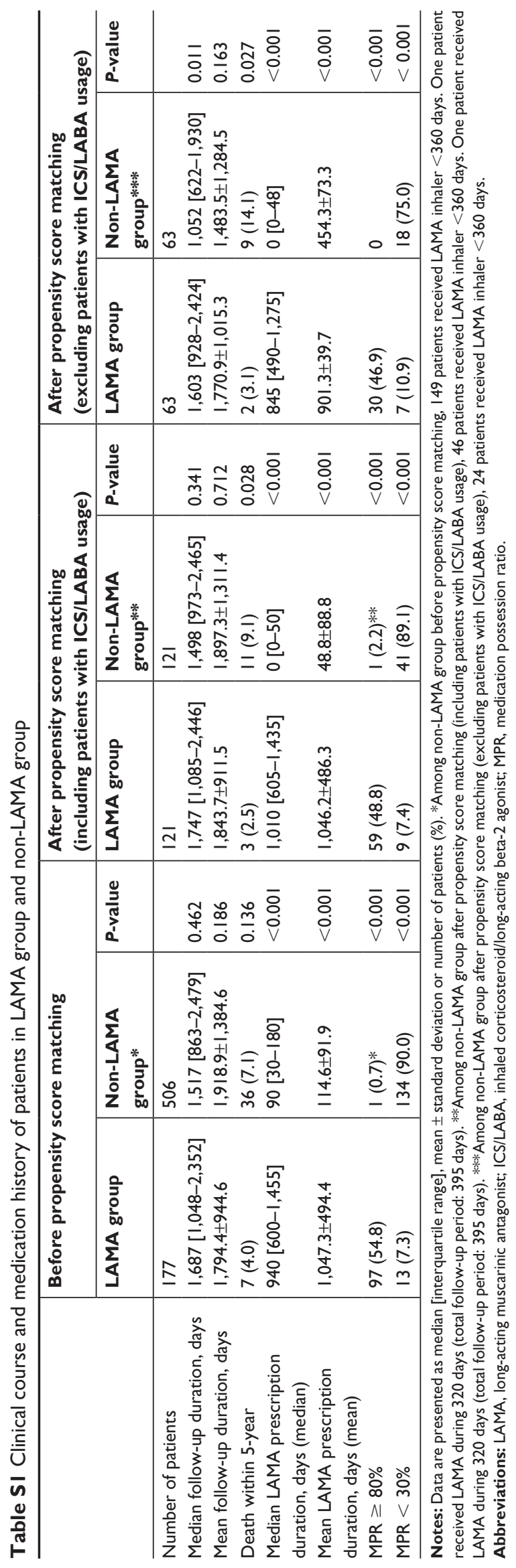




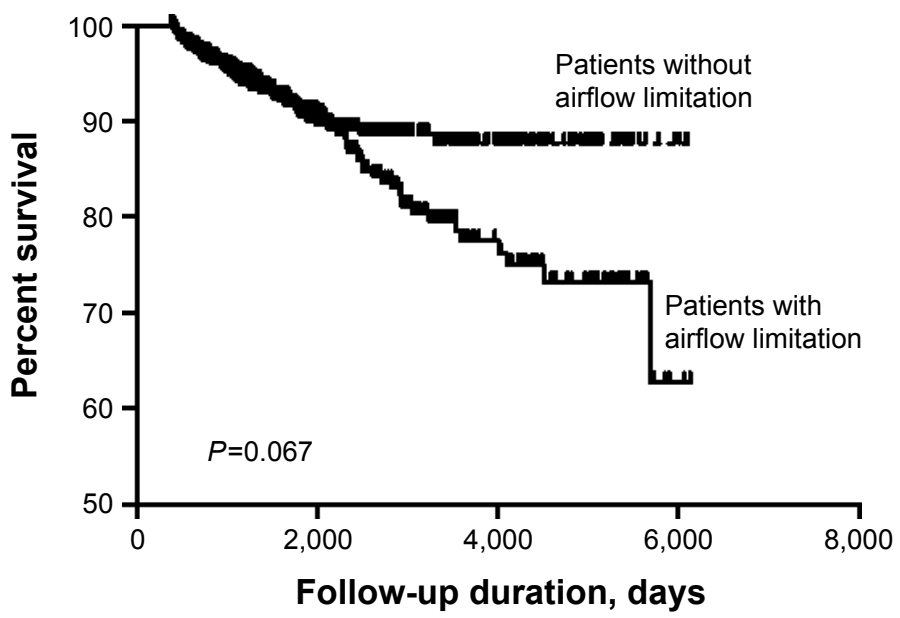

Figure SI Comparison of Kaplan-Meier survival curves between patients with airflow limitation and without airflow limitation. Note: $P$-value from Log rank test.

Table S2 Baseline characteristics of patients in with or without airflow limitation groups

\begin{tabular}{|c|c|c|c|}
\hline & $\begin{array}{l}\text { With airflow } \\
\text { limitation group }\end{array}$ & $\begin{array}{l}\text { Without airflow } \\
\text { limitation group }\end{array}$ & $P$-value \\
\hline Number of patients & $683(55.8)$ & $542(44.2)$ & \\
\hline Age, years & $62.0 \pm 11.2$ & $56.4 \pm 13.5$ & $<0.001$ \\
\hline Male gender & 47I (69.0) & $300(55.4)$ & $<0.001$ \\
\hline Body mass index, $\mathrm{kg} / \mathrm{m}^{2}$ & $21.9 \pm 3.4$ & $21.5 \pm 3.6$ & 0.032 \\
\hline Ever smoker & $404(59.2)$ & $246(45.4)$ & $<0.001$ \\
\hline mMRC dyspnea scale & & & $<0.001$ \\
\hline-0 & $223(32.8)$ & $333(6 I .4)$ & \\
\hline-1 & $235(34.6)$ & II $2(20.7)$ & \\
\hline-2 & $124(18.2)$ & $66(12.2)$ & \\
\hline-3 & $69(10.1)$ & $23(4.2)$ & \\
\hline-4 & $29(4.3)$ & $8(1.5)$ & \\
\hline Charlson Comorbidity Index & $1.5 \pm 1.4$ & $1.0 \pm 1.3$ & $<0.001$ \\
\hline Concomitant asthma & $90(13.2)$ & $15(2.6)$ & $<0.001$ \\
\hline LAMA usage over 360 days & $|7|(25.0)$ & $23(4.2)$ & $<0.001$ \\
\hline ICS/LABA usage over 360 days & 177 (25.9) & $31(5.7)$ & $<0.001$ \\
\hline \multicolumn{4}{|l|}{ Pulmonary function tests } \\
\hline $\mathrm{FEV}_{1}, \%$ predicted & $50.6 \pm 19.5$ & $78.2 \pm 24.9$ & $<0.001$ \\
\hline FVC, \% predicted & $69.0 \pm 18.9$ & $73.9 \pm 23.2$ & $<0.001$ \\
\hline $\mathrm{FEV}_{1} / \mathrm{FVC}$ ratio, \% & $53.1 \pm I I .4$ & $80.5 \pm 0.08$ & $<0.001$ \\
\hline DLco, \% predicted & $67.8 \pm 21.6$ & $75.7 \pm 26.4$ & $<0.001$ \\
\hline Respiratory admission within 2 years & $77(11.3)$ & $67(12.4)$ & 0.557 \\
\hline $\mathrm{X}$-ray severity ( 0 to 6$)$ & $3.0 \pm 1.3$ & $2.3 \pm 1.5$ & $<0.001$ \\
\hline Long-term oxygen therapy & $59(8.6)$ & $31(5.7)$ & 0.052 \\
\hline
\end{tabular}

Notes: Data are presented as mean \pm standard deviation or number of patients (\%), unless otherwise indicated. Airflow limitation group was defined as patients who had FEV $/$ /FVC $<70 \%$.

Abbreviations: LAMA, long-acting muscarinic antagonist; ICS/LABA, inhaled corticosteroid/long-acting beta-2 agonist; DLco, diffusing capacity for carbon monoxide.

Therapeutics and Clinical Risk Management

Dovepress

\section{Publish your work in this journal}

Therapeutics and Clinical Risk Management is an international, peerreviewed journal of clinical therapeutics and risk management, focusing on concise rapid reporting of clinical studies in all therapeutic areas, outcomes, safety, and programs for the effective, safe, and sustained use of medicines. This journal is indexed on PubMed Central, CAS,
EMBase, Scopus and the Elsevier Bibliographic databases. The manuscript management system is completely online and includes a very quick and fair peer-review system, which is all easy to use. Visit http://www.dovepress.com/testimonials.php to read real quotes from published authors.

Submit your manuscript here: http://www.dovepress.com/therapeutics-and-clinical-risk-management-journal 